\title{
Validation of the GenoType MTBDRplus assay for diagnosis of multidrug resistant tuberculosis in South Vietnam
}

\author{
Mai NT Huyen1, Edine W Tiemersma*2,3, Nguyen TN Lan1, Frank GJ Cobelens³, Nguyen H Dung ${ }^{1}$, Dinh N Sy4, \\ Tran N Buu' ${ }^{1}$, Kristin Kremer ${ }^{5}$, Pham T Hang ${ }^{1}$, Maxine Caws ${ }^{6}$, Richard O'Brien ${ }^{7}$ and Dick van Soolingen 5,8
}

\begin{abstract}
Background: To control multidrug resistant tuberculosis (MDR-TB), the drug susceptibility profile is needed to guide therapy. Classical drug susceptibility testing (DST) may take up to 2 to 4 months. The GenoType MTBDRplus test is a commercially available line-probe assay that rapidly detects Mycobacterium tuberculosis (MTB) complex, as well as the most common mutations associated with rifampin and isoniazid resistance.
\end{abstract}

We assessed sensitivity and specificity of the assay by using a geographically representative set of MTB isolates from the South of Vietnam.

Methods: We re-cultured 111 MTB isolates that were MDR, rifampin-resistant or pan-susceptible according to conventional DST and tested these with the GenoType MTBDRplus test.

Results: By conventional DST, 55 strains were classified as MDR-TB, four strains were rifampicin mono-resistant and 52 strains were susceptible to all first-line drugs. The sensitivity of the GenoType MTBDRplus was $93.1 \%$ for rifampicin, $92.6 \%$ for isoniazid and $88.9 \%$ for the combination of both; its specificity was 100\%. The positive predictive value of the GenoType MTBDRplus test for MDR-TB was 100\% and the negative predictive value $90.3 \%$.

Conclusions: We found a high specificity and positive predictive value of the GenoType MTBDRplus test for MDR-TB which merits its use in the MDR-TB treatment program in Vietnam.

\section{Background}

Tuberculosis (TB) is an important disease in developing countries [1]. A major concern is the occurrence of multidrug resistant (MDR) TB [2] which is characterized by resistance to both rifampicin and isoniazid (INH). MDRTB is difficult to treat and associated with increased treatment failures and relapses. In patients with previously untreated pulmonary TB, inappropriate treatment may lead to selection for bacteria with drug resistance associated mutations [3].

Vietnam ranks $14^{\text {th }}$ among the countries with the highest burden of TB; the incidence of TB is highest in the southern part of the country [1]. In 2005, South Vietnam notified 29,789 new smear positive cases yielding an esti-

* Correspondence: TiemersmaE@kncvtbc.nl

2 KNCV Tuberculosis Foundation, PO Box 146, 2501 CC The Hague, The Netherlands

Full list of author information is available at the end of the article mated prevalence of 92.8 per 100,000 (NTP, unpublished data, 2006). M. tuberculosis resistance to INH is common (16-25\% among new patients) [4,5]. Among patients experiencing a first episode of TB these two studies reported MDR-TB rates of 2 and 4\%, and of $23 \%$ and $27 \%$ among previously treated patients, respectively $[4,5]$, whereas $80 \%$ chronic patients had MDR-TB [6]. Genetically, approximately half of the strains belongs to the East-African Indian clade whereas the other half are of the Beijing genotype, which was found to be strongly associated with (multi-)drug resistance [7,8].

To control MDR-TB, drug resistance patterns should be available to guide the therapy of the patient. However, phenotypic drug susceptibility testing (DST) is a timeconsuming process because it requires culturing, which may take up to two months or longer. As long as no DST results are available, the patient will be treated with stan- 
dard first-line anti-TB drugs. Rapid diagnosis of MDR-TB will permit an earlier start with second-line drug treatment for patients with MDR-TB and may thus decrease the risk of treatment failure, relapse, amplification of DR, and continuing transmission of MDR-TB.

The vast majority of resistance to rifampicin is caused by mutations located in the 81-bp hotspot region of the rpoB gene [9]. Mutations conferring resistance to INH are located at several genomic loci ( $k a t G$, inhA and kasA) [10-14]. Varying by geographic area, 50 to $100 \%$ of INH resistant strains has mutations in codon 315 of the katG gene or in the promoter region of the inh $A$ gene $[13,15,16]$.

The GenoType MTBDRplus assay (Hain Lifescience, Nehren, Germany) is a commercially available assay that combines detection of MTB complex with prediction of resistance to rifampicin and INH. In the assay a multiplex PCR is followed by hybridization of the obtained DNA amplicons to membrane-bound probes. The assay combines detection of MTB complex with detection of mutations in the 81-bp hotspot region of rpoB, at codon 315 of the katG gene and in the $i n h A$ promoter region. It was found to have high sensitivity and high specificity for rifampicin and INH resistance and performs well when applied directly to AFB smear-positive sputum specimens [15,17-20]. A recent meta-analysis pooled all these studies and calculated pooled sensitivity and specificity rates of 99\% (95\% confidence interval (CI), 96\%-100\%) and $99 \%$ (95\% CI, 98\%-100\%) respectively for rifampicin resistance, and of 96\% (93-98\%) and 100\% (99-100\%), respectively for isoniazid resistance [21].

In June 2008, the World Health Organization (WHO) endorsed the use of molecular line-probe assays for MDR-TB screening [22], and the GenoType MTBDRplus assay has since been introduced for routine practice in various countries [15,17-20,23]. The WHO recommends that before using the assay in routine TB treatment and control, the performance of the assay in relation to the locally circulating $M$. tuberculosis bacteria should be validated [22].

The National Tuberculosis Control Program of Vietnam intends to use this test in support of Programmatic Management of DR-TB (PMDT) on sputum specimens of all MDR-TB suspects (i.e., those failing category 1 treatment and those being smear-positive after 3 months of category 2 treatment). The Genotype MTBDRplus assay will be used to select patients with rifampicin resistant isolates for PMDT. Therefore, we assessed the test's sensitivity and specificity in diagnosing MDR-TB at the laboratory of Pham Ngoc Thach Hospital (PNTH) using a geographically representative set of $M$. tuberculosis isolates with known phenotypic resistance patterns from the South of Vietnam.

\section{Methods}

\section{Study population}

We selected MTB isolates from the latest nationwide TB drug resistance survey (DRS) in Vietnam conducted in 2004-2005. This survey was carefully designed as to cover all geographical parts of Vietnam and the set of samples thus provided a national estimate of drug resistance for Vietnam. DST was done by the two national reference laboratories, one of which was at PNTH in Ho Chi Minh City. The DRS was part of the WHO/IUATLD Global Project on TB Drug Resistance Surveillance and followed WHO guidelines [24]. PNTH's laboratory participates in an annual international proficiency study on DST together with laboratories in Korea and Australia, with results that are concordant to those of other laboratories for more than $95 \%$ of the tests.

Complete DST results were available for 1,826 patients with smear-positive TB from 80 different TB clinics throughout the country. Of these, 1,044 (57\%) specimens were collected in the South of Vietnam and tested in PNTH (910 from new patients and 134 from previously treated patients). Sputum specimens were processed according to standard procedures [24]. After centrifugation, sediment was inoculated on Löwenstein-Jensen (LJ) medium and incubated at $37^{\circ} \mathrm{C}$ for 4 to 8 weeks followed by species identification of culture-positive samples. DST for isoniazid $(0.2 \mu \mathrm{g} / \mathrm{ml})$, streptomycin $(4 \mu \mathrm{g} / \mathrm{ml})$, ethambutol $(2 \mu \mathrm{g} / \mathrm{ml})$, and rifampicin $(40 \mu \mathrm{g} / \mathrm{ml})$ was performed using LJ media following the proportion method [25]. Isolates from all 30 new and 29 re-treatment cases that were either identified as MDR-TB $(n=55)$ or resistant to rifampicin $(n=4)$ by phenotypic DST were included in this study. In addition, from the isolates that were susceptible to all tested first-line drugs from new and re-treatment patients, we randomly selected 52 isolates, so that the total number of tested strains was 111 .

\section{GenoType ${ }^{\circ}$ MTBDRplus testing}

GenoType MTBDRplus testing was performed blinded from the phenotypic DST results. The selected MTB isolates were re-cultured from the $-70^{\circ} \mathrm{C}$ freezer and subjected to the GenoType MTBDRplus test according to the manufacturer's recommendations http://www.hainlifescience.de. By multiplex PCR the rpoB, kat $G$ and inh $A$ genes were amplified and the resulting biotin-labeled amplicons were hybridized to DNA probes bound to membrane strips. Hybridization was detected by addition of a streptavidin/alkaline phosphatase (AP) conjugate and an AP mediated staining reaction. For each gene, the GenoType MTBDRplus assay tests for presence of socalled wild-type (WT) and mutant (MUT) probes, the first comprising the most important resistant areas of the respective genes and the second some of the most common resistance mediating mutations. Next to that, the 
TUB zone hybridizes with amplicons generated from all members of the Mycobacterium complex and can thus serve for species identification. The membrane-bound DNA probes included eight $r p o B$ wild-type probes, four rpoB mutant probes (with D516V, H526Y, H526D, and S531L mutations), one katG wild-type probe, two katG mutant probes (with S315T1 and S315T2 mutations), two inhA wild-type probes and four inhA mutant probes (with C15T, A16G, T8C, and T8A mutations) [26]. Following the manufacturer's instructions http://www.hainlifescience.de, susceptibility to isoniazid and rifampicin was defined as hybridization to all the wild type probes and no hybridization to the mutant probes. A strain that revealed hybridization to both a mutant probe and to the corresponding wild type probe was considered to represent a heterogeneous population of bacteria or a mixed infection of a sensitive and a resistant strain.

\section{Species identification}

M. tuberculosis was identified by smear microscopy followed by a positive niacine reaction [27]. Further species identification was performed using Innolipa Mycobacteria v2 (Innogenetics, Gent, Belgium) if a discrepancy was found between initial species identification and results from the GenoType MTBDRplus assay (i.e., no hybridization with the TUB band).

\section{DNA fingerprinting and sequencing}

In order to identify possible cases of mixed infection, spoligotyping [28] and IS6110 restriction fragment length polymorphism (RFLP) [29] were applied to single colonies growing on standard culture medium and medium supplemented with tuberculostatics. DNA patterns were scanned and analysed by using Gelcompar software (Applied Maths, Sint-Martens-Latum, Belgium) as previously described [30]. The Beijing genotype was defined by spoligotyping as any isolate without Direct Repeat spacers 1-34 and the presence of $\geq 3$ of the spacers 35-43 [31]. Other genotypes were defined as described by Brudey et al. [32], including the Vietnam genotype (EAIVNM) that belongs to the East African Indian genotype family of $M$. tuberculosis and is the most frequent genotype in this study site [8].

Sequencing of the rifampin resistance-determining region (RRDR) region of the $r p o B$ gene was performed for strains that had discordant results for rifampicin according to conventional DST and the GenoType MTBDRplus test. The $350 \mathrm{bp}$ fragment of the rpoB gene was amplified using outer primers RPOBF (5'GGGAGCGGATGACCACCCA3') and RPOBR (5'GCGGTACGGCGTTTCGATGAAC-3'). The primers were designed using Primer Express version 2.0 software (Applied Biosystems Inc, Foster City, CA, USA) [33].

\section{Ethical approval}

The study protocol was approved by the Research Board of Pham Ngoc Thach hospital. Since this study used stored isolates with known drug resistance patterns and no additional procedures on the patients were involved, individual informed consent was not obtained.

\section{Statistical Methods}

Data were double entered in EpiData version 3.1 http:// www.epidata.dk by two separate study assistants. Discrepancies were checked against the crude data. Chisquared tests were performed using Epi Info version 6.04 http://www.cdc.gov/epiinfo/. Results were considered significant at $\mathrm{P}<0.05$.

\section{Results}

\section{Concordance between conventional DST and GenoType} MTBDRplus assay

Of 111 isolates tested, there was one MDR strain that lacked the TUB band. Although this strain was earlier identified as $M$. tuberculosis, further species identification identified the strain as $M$. avium-intracellulare (MAIS). Spoligotyping after re-culturing this isolate showed that it was a mixture of $M$. tuberculosis and MAIS. Since the GenoType MTBDRplus assay did not identify this strain as MDR-TB, all analyses describing the assay's performance include 110 isolates, of which 58 were resistant to rifampicin by conventional DST.

Based on phenotypic DST, 54 strains were MDR-TB, four strains were rifampicin mono-resistant and 52 strains were susceptible to all first-line drugs. Considering the phenotypic DST method as the gold standard, the GenoType MTBDRplus test correctly identified 48 of 54 MDR-TB strains (88.9\%, 95\% CI: 77.4-95.8\%); 54 of 58 rifampicin resistant strains (93.1\%, 95\% CI: 83.3-98.1\%); 50 of $54 \mathrm{INH}$ resistant strains $(92.6 \%, 95 \% \mathrm{CI}: 82.1-$ 97.9\%); and all susceptible strains (100\%, 95\% CI: $93.2-$ $100 \%)$. The specificity for detecting MDR-TB was $100 \%$. The overall concordance of the GenoType MTBDRplus test and phenotypic DST was 94.5\% (104/110). Sensitivities, specificities and predictive values are listed in Table 1.

Sequencing the RRDR region of the $r p o B$ gene of the four strains with discordant results for rifampicin revealed that one strain possessed the H526L mutation which is not present on the membrane strips; in the three remaining strains no mutations were detected in the $r p o B$ gene.

\section{Frequency of drug resistance associated mutations}

Mutation patterns produced by the GenoType MTBDRplus test are displayed in Table 2. Among the 54 RIF resistant TB strains detected by this test, the frequency of rpoB mutations was: 27 S531L (50\%), 6 H526Y (10.9\%), 3 
Table 1: The sensitivity, specificity, positive predictive value (PPV) and negative predictive value (NPV) and 95\% confidence intervals of the GenoType ${ }^{\circ}$ MTBDRplus assay on 111 M. tuberculosis cultures isolates in the South of Vietnam.

\begin{tabular}{llll}
\hline & Rifampicin & Isoniazid & Multi drug resistance \\
\hline Sensitivity & $93.1 \%(83.3-98.1)$ & $92.6 \%(82.1-97.9)$ & $88.9 \%(77.4-95.8)$ \\
Specificity & $100 \%(93.2-100)$ & $100 \%(93.6-100)$ & $100 \%(93.6-100)$ \\
PPV & $100 \%(93.4-100)$ & $100 \%(92.9-100)$ & $100 \%(92.6-100)$ \\
NPV & $92.9 \%(82.7-98.0)$ & $93.3 \%(83.8-98.1)$ & $90.3 \%(80.1-96.4)$ \\
\hline
\end{tabular}

D516V (5.5\%), 1 H526D (1.8\%), 7 missing WT2 (12.7\%), 10 missing WT3 (18.1\%), 6 missing WT4 (10.9\%), 14 missing WT7 (25.5\%), 26 missing WT8 (48\%), and no case missing WT1, WT5 or WT6.

Among $50 \mathrm{INH}$ resistant TB strains as identified by the GenoType MTBDRplus test, $k a t G$ mutations occurred in $43(86 \%)$ and $i n h A$ mutations in 9 strains (18\%). Two of the $43(5 \%)$ strains with a $k a t G$ codon 315 mutation had an additional mutation in the $i n h A$ promoter region. The most frequently observed $k a t G$ mutation was katG
S315T1 (in 38 of 43 strains, 88.4\%), whereas katG S315T2 (2.3\%) and unknown mutations (i.e., no hybridization to the katG WT nor to either of the mutation probes, 9.3\%) occurred less frequently. All 9 strains with a mutation in the inhA promoter region had an inhA C15T mutation (Table 2).

\section{Detection of mixed bacterial populations}

With this rapid assay four possible mixtures were detected, although one of these was not identified by the

Table 2: Mutation patterns following from the GenoType ${ }^{\circledR}$ MTBDRplus assay.

\begin{tabular}{|c|c|c|c|c|}
\hline rpoB mutations & katG mutations & inhA mutations & Frequency & Proportion \\
\hline D516V & S315T1 & -- & 1 & 0.9 \\
\hline D516V & unknown * & -- & 1 & 0.9 \\
\hline D516V & -- & $\mathrm{C} 15 \mathrm{~T}$ & 1 & 0.9 \\
\hline H526D & S315T1 & -- & 1 & 0.9 \\
\hline H526Y & S315T1 & -- & 5 & 4.6 \\
\hline S531L & unknown * & -- & 2 & 1.8 \\
\hline S531L & S315T1 & $\mathrm{C} 15 \mathrm{~T}$ & 1 & 0.9 \\
\hline S531L & S315T1 & -- & 16 & 14.6 \\
\hline S531L & S315T2 & -- & 1 & 0.9 \\
\hline S531L & -- & $\mathrm{C} 15 \mathrm{~T}$ & 4 & 3.6 \\
\hline S531L & -- & -- & 2 & 1.8 \\
\hline H526Y + S531L & -- & -- & 1 & 0.9 \\
\hline unknown * & S315T1 & -- & 13 & 11.8 \\
\hline unknown * & -- & -- & 3 & 1.8 \\
\hline unknown * & unknown * & $\mathrm{C} 15 \mathrm{~T}$ & 1 & 0.9 \\
\hline unknown * & -- & C15T & 1 & 0.9 \\
\hline-- & S315T1 & -- & 1 & 0.9 \\
\hline-- & -- & $\mathrm{C} 15 \mathrm{~T}$ & 1 & 0.9 \\
\hline \multicolumn{3}{|c|}{ Total number of strains with any mutations } & 56 & 50.9 \\
\hline \multirow[t]{2}{*}{--} & -- & -- & 54 & 49.1 \\
\hline & & Total number of strains & 110 & 100 \\
\hline
\end{tabular}

* unknown mutation: no hybridization to one or more of the wild type probes nor to any of the mutation probes. 
assay as $M$. tuberculosis due to a lacking TUB band and was later identified to contain MAIS. These four phenotypically rifampicin resistant isolates were demonstrated to carry mutations in the $r p o B$ gene and/or in the katG gene or the inhA promoter region, but did not lack hybridization on any of the wild type probes. By using DNA fingerprinting one of these isolates was confirmed to be a mixture of two MTB strains (spoligotype T1 and an undefined type; RFLP type T1 and Beijing), and the isolate lacking the TUB band (number 12647) was identified as a mixture of a MTB strain (spoligotype $U$ ) and a non-tuberculous mycobacterium (note that spoligotyping yielded a weak signal for $M$. tuberculosis for one single colony culture of this isolate) (Table 3, Figure 1). In the two remaining samples mixed bacterial populations could not be detected. After spoligotyping which revealed no differences as it has a very low resolution among Beijing strains, we also performed IS6110 RFLP typing on single colony cultures of each of these two samples and found they all had identical banding patterns (Table 3).

\section{Discussion}

In this study, the GenoType MTBDRplus assay correctly identified $93.1 \%, 92.6 \%$ and $88.9 \%$ of the rifampicin, INH and combined resistance (MDR), respectively and had $100 \%$ specificity for each. The sensitivity of detection of rifampicin resistance was similar to that reported from Germany, Italy, Finland, France, Denmark, Turkey and Taiwan (92-100\%, p > 0.05) [15,17-20,26,34,35]. The GenoType MTBDRplus assay failed to detect four (6.8\%) of the rifampicin resistant strains in our study, which was caused either by a rare mutation which is not present on the strips $(n=1)$ or by probable mutations in other genomic regions of the $r p o B$ gene $(n=3)$. The sensitivity for detection of isoniazid resistance in our study was 91.2\%, which was similar to reports from Germany, Fin- land, Denmark and Taiwan (84 - 100\%, p > 0.05) [15,17$20,26,34,35]$, but higher than reported from Turkey, Italy, France and the Caribbean (35-73\%, P $<0.05)$ $[17,18,20,36]$. For MDR-TB the sensitivity of the test was somewhat lower than reported from other research [21].

The distribution of mutations identified in our study is significantly different from that reported from other continents. We found that the S531L mutation in the $r p o B$ gene occurred most frequently (50\%) among rifampicin resistant strains. This mutation occurred even more frequently in a collection of isolates from South Africa (70.5\%, $\mathrm{p}=0.014)$ [23]. In our study only $36(66.7 \%)$ MDR-TB strains had a mutation that could be identified by one of the four rpoB mutant probes present on the strip, whereas this was much higher in South Africa (91\% $(81 / 89)$ ) [23]. Thus, the assay performs better detecting rpoB specific mutations that confer rifampicin resistance in South Africa than in Vietnam. For INH resistance, mutations in the katG gene were by far most common (86\%) and the S315T1 mutation was found most frequently $(88.4 \%)$ in our population. From South Africa, Van Rie et al [37] reported similar results, whereas Barnard and colleagues [23] reported that this mutation occurred less frequently $(37.6 \% ; \mathrm{p}=0.01)$. In our study $18 \%$ of INH resistant MTB strains carried a mutation in the inhA promoter region (invariably $\mathrm{C} 15 \mathrm{~T}$ ) which is considerably lower than the $40 \%$ reported in Barnard's study $(p=0.007)$. It should be noted that we only tested MDR-TB isolates, whereas Barnard's study also included INH monoresistant strains and MDR-TB may be primarily associated with $k a t G$ mutations that generally confer high levels of INH resistance [38].

The GenoType MTBDRplus assay can detect mixtures of drug resistant and drug susceptible bacterial populations. In this study four mixtures were found: three mixtures of $M$. tuberculosis strains and one mixture of a $M$.

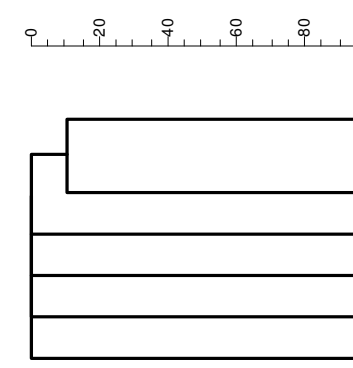

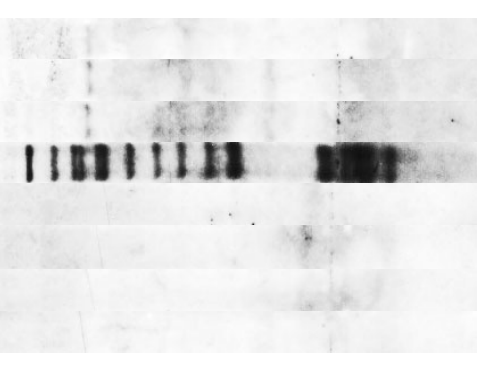

IS6110 RFLP

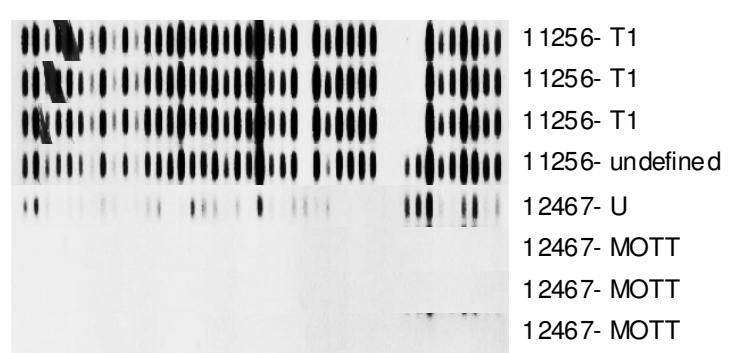

SPOLIGOTYPING

Figure 1 Patterns of multiple Mycobacterium spp. infections as obtained by RFLP and spoligotyping techniques. The first three isolates have only one band by RFLP (non-Beijing) and spoligotype T1; the $4^{\text {th }}$ sample is a mixture of Beijing genotype (as obtained by RFLP) and spoligotype T1. The $5^{\text {th }}$ sample has no RFLP banding pattern and an undefined spoligotype, whereas for the last three isolates no banding patterns were found by RFLP and spoligotyping, probably as a result of the presence of non-tuberculous mycobacteria (NTM). 
Table 3: Identification of mixed TB infections by spoligotyping and RFLP.*

\begin{tabular}{|c|c|c|c|c|c|c|c|}
\hline \multirow[t]{2}{*}{ Strain no. } & \multirow[t]{2}{*}{ TUB } & \multicolumn{2}{|c|}{ Rifampin } & \multicolumn{2}{|c|}{ Isoniazid } & \multirow[t]{2}{*}{ Spoligotype } & \multirow{2}{*}{$\begin{array}{l}\text { RFLP type + } \\
\text { spoligotype }\end{array}$} \\
\hline & & WT & MUT & WT & MUT & & \\
\hline 10484 & + & + & Mut 2A \& 3 & + & - & Beijing & Identical Beijing \\
\hline 11256 & + & + & Mut 3 & + & katG Mut 1 \&inhA Mut 1 & $\begin{array}{l}\mathrm{T} 1+ \\
\text { undefined } \\
\text { type }\end{array}$ & T1 +BEIJING \\
\hline 11901 & + & + & Mut 3 & + & $\operatorname{inh} A$ Mut 1 & Beijing & Identical Beijing \\
\hline 12467 & - & - & + & + & katG Mut 1 & $U+$ No band & $U+$ no band \\
\hline
\end{tabular}

${ }^{*}$ TUB: M. tuberculosis confirmation band; WT: wild type; MUT: mutant

tuberculosis strain and an $M$. avium complex strain. This indicates that even in a high prevalence area like Vietnam a minor proportion of the TB cases is caused by a mixture of non-tuberculous mycobacteria and MTB. The GenoType MTBDRplus assay may not be sensitive enough to be used for species identification in case of mixed bacterial populations, since the $M$. tuberculosis and M. avium mixture revealed no TUB band.

Mixed infections were confirmed by typing a limited number of single colony cultures by spoligotyping and RFLP. In two samples that seemed to consist of a mixture when tested with the GenoType MTBDRplus assay, presence of a mixed infection could not be confirmed which could have been the result of testing only a limited number of single colony cultures.

With the $100 \%$ specificity of the GenoType MTBDRplus assay to detect MDR in M. tuberculosis isolates, no patient would be inappropriately treated with category 4 (MDR-TB) treatment if this test would be used in routine for rapid MDR-TB diagnosis. On the other hand, $6.9 \%$ of patients would not receive appropriate category 4 treatment (which is based on detection of rifampicin resistance) if identification of MDR-TB patients is done using only the GenoType MTBDRplus test.

\section{Conclusions}

Overall, the GenoType MTBDRplus test is reliable, rapid and easy to perform for the simultaneous detection of rifampicin and INH resistance in M. tuberculosis. With high sensitivity for detection of rifampin resistance and high specificity for MDR, we conclude that this test strongly facilitates adequate treatment of MDR-TB patients, long before the results of conventional DST are available. Because discordance still exists between the conventional and molecular approach of DST and susceptibility of bacteria to drugs is defined as inhibition of growth, we recommend that the GenoType MTBDRplus test should serve as an early guidance of therapy, which should be followed by a phenotypic DST confirmation for all suspected MDR-TB patients. Incorporation of the molecular test in the National Tuberculosis Program is an important step forward in the rapid diagnosis of MDRTB among suspected patients in the PMDT program. The application of the molecular test directly to clinical material with sufficient bacteria will further speed up the turnaround time of the rapid diagnosis of MDR-TB and will be the next step of implementation.

\section{List of abbreviations}

AFB: acid-fast bacilli; AP: alkaline phosphatase; CI: confidence interval; DRS: drug resistance survey; DST: drug susceptibility testing; FIND: Foundation for Innovative New Diagnostics; INH: isoniazid; IUATLD: International Union Against Tuberculosis and Lung Disease; LJ: Löwenstein-Jensen; MAIS: Mycobacterium avium-intracellulare; MDR-TB: multidrug resistant tuberculosis; MTB: Mycobacterium tuberculosis; NPV: negative predictive value; PMDT: Programmatic Management of drug resistant TB; PNTH: Pham Ngoc Thach Hospital; PPV: positive predictive value; TB: tuberculosis; RFLP: restriction fragment length polymorphism; RRDR: rifampin resistance-determining region; WHO: the World Health Organization.

Competing interests

The authors declare that they have no competing interests.

\section{Authors' contributions}

$\mathrm{MH}$ was involved in data collection and analysis and drafted the manuscript. ET and FC were involved in the conception, design and coordination of the study. $\mathrm{NL}$ was involved in the conception of the study and coordinated the study including collection of the strains. DS, ND, and TB were involved in conception of the study and in coordinating the collection of the strains used in this study. KK and DS gave guidance to the analysis and interpretation of the molecular results. $\mathrm{PH}$ did the drug susceptibility tests for this study. $\mathrm{RO}$ was involved in the conception and design of the study. MC supervised the sequencing and strain identification. All authors read and approved the final manuscript.

\section{Acknowledgements}

This research was funded by the Foundation for Innovative New Diagnostics (FIND), Geneva, Switzerland, and the KNCV Tuberculosis Foundation, The Hague, The Netherlands. We thank the staff of the laboratory of Pham Ngoc 
Thach Hospital for performing DST and GenoType" MTBDRplus testing and for patient recruitment.

We thank the staff of the Mycobacterium laboratory of the Oxford University Clinical Research Unit for sequencing and identification of non-tuberculous mycobacteria.

We thank Yuli You at Biomedia Group, Singapore, and staff at the Tuberculosis Reference Laboratory, RIVM, Bilthoven, The Netherlands for providing technical assistance.

\section{Author Details}

1Ph?m Ng?c Th?ch hospital, 120 Hung Vuong, district 5, Ho Chi Minh City, Viet Nam, 2KNCV Tuberculosis Foundation, PO Box 146, 2501 CC The Hague, The Netherlands, ${ }^{3}$ Center for Poverty-related Communicable Diseases, Amsterdam Institute of Global Health and development, Academic Medical Center, Meibergdreef 9, 1105 AZ Amsterdam, The Netherlands, 4National Lung Hospital, 463 Hoang Hoa Tham, Ba Dinh district, Ha Noi, Viet Nam,

${ }^{5}$ Tuberculosis Reference Laboratory, RIVM, PO Box 1, 3720 BA Bilthoven, The Netherlands, 6 Wellcome Trust Major Overseas Programme, Oxford University Clinical Research Unit, Hospital for Tropical Diseases, 190 Ben Ham Tu, District 5, Ho Chi Minh City, Viet Nam, ${ }^{7}$ Foundation for Innovative New Diagnostics (FIND), Avenue de Budé 16, 1202 Geneva, Switserland and ${ }^{8}$ Departments of Pulmonary Diseases and Medical Microbiology, Radboud University, PO box 9101, 6500 HB Nijmegen, The Netherlands

Received: 18 December 2009 Accepted: 3 June 2010

Published: 3 June 2010

\section{References}

1. WHO: Global tuberculosis control: surveillance, planning, financing. WHO report 2009 Geneva: World Health Organization; 2009.

2. Wright A, Zignol M, Van Deun A, Falzon D, Gerdes SR, Feldman K, Hoffner S, Drobniewski F, Barrera L, van Soolingen D, et al.: Epidemiology of antituberculosis drug resistance 2002-07: an updated analysis of the Global Project on Anti-Tuberculosis Drug Resistance Surveillance. Lancet 2009, 373(9678):1861-1873.

3. Mitchison DA: How drug resistance emerges as a result of poor compliance during short course chemotherapy for tuberculosis. Int $\mathrm{J}$ Tuberc Lung Dis 1998, 2(1):10-15.

4. Quy HT, Buu TN, Cobelens FG, Lan NT, Lambregts CS, Borgdorff MW: Drug resistance among smear-positive tuberculosis patients in Ho Chi Minh City, Vietnam. Int J Tuberc Lung Dis 2006, 10(2):160-166.

5. Huong NT, Lan NT, Cobelens FG, Duong BD, Co NV, Bosman MC, Kim SJ, van Soolingen D, Borgdorff MW: Antituberculosis drug resistance in the south of Vietnam: prevalence and trends. J Infect Dis 2006, 194(9):1226-1232.

6. Quy HT, Lan NT, Borgdorff MW, Grosset J, Linh PD, Tung LB, van Soolingen $D$, Raviglione M, Co NV, Broekmans J: Drug resistance among failure and relapse cases of tuberculosis: is the standard re-treatment regimen adequate? Int J Tuberc Lung Dis 2003, 7(7):631-636.

7. Anh DD, Borgdorff MW, Van LN, Lan NT, van Gorkom T, Kremer K, van Soolingen D: Mycobacterium tuberculosis Beijing genotype emerging in Vietnam. Emerg Infect Dis 2000, 6(3):302-305.

8. Buu TN, Huyen MN, Lan NT, Quy HT, Hen NV, Zignol M, Borgdorff MW, Cobelens FG, van Soolingen D: The Beijing genotype is associated with young age and multidrug-resistant tuberculosis in rural Vietnam. Int J Tuberc Lung Dis 2009, 13(7):900-906.

9. Telenti A, Imboden P, Marchesi F, Lowrie D, Cole S, Colston MJ, Matter L, Schopfer K, Bodmer T: Detection of rifampicin-resistance mutations in Mycobacterium tuberculosis. Lancet 1993, 341(8846):647-650.

10. Banerjee A, Dubnau E, Quemard A, Balasubramanian V, Um KS, Wilson T, Collins D, de Lisle G, Jacobs WR Jr: inhA, a gene encoding a target for isoniazid and ethionamide in Mycobacterium tuberculosis. Science 1994, 263(5144):227-230.

11. Kelley CL, Rouse DA, Morris SL: Analysis of ahpC gene mutations in isoniazid-resistant clinical isolates of Mycobacterium tuberculosis. Antimicrob Agents Chemother 1997, 41(9):2057-2058.

12. Mdluli K, Slayden RA, Zhu Y, Ramaswamy S, Pan X, Mead D, Crane DD, Musser JM, Barry CE: Inhibition of a Mycobacterium tuberculosis betaketoacyl ACP synthase by isoniazid. Science 1998, 280(5369):1607-1610.

13. Musser JM, Kapur V, Williams DL, Kreiswirth BN, van Soolingen D, van Embden JD: Characterization of the catalase-peroxidase gene (kat $G$ ) and inhA locus in isoniazid-resistant and -susceptible strains of Mycobacterium tuberculosis by automated DNA sequencing: restricted array of mutations associated with drug resistance. J Infect Dis 1996 173(1):196-202.

14. Ramaswamy S, Musser JM: Molecular genetic basis of antimicrobial agent resistance in Mycobacterium tuberculosis: 1998 update. Tuber Lung Dis 1998, 79(1):3-29.

15. Hillemann D, Weizenegger M, Kubica T, Richter E, Niemann S: Use of the genotype MTBDR assay for rapid detection of rifampin and isoniazid resistance in Mycobacterium tuberculosis complex isolates. J Clin Microbiol 2005, 43(8):3699-3703.

16. Hillemann D, Kubica T, Agzamova R, Venera B, Rusch-Gerdes S, Niemann $\mathrm{S}$ : Rifampicin and isoniazid resistance mutations in Mycobacterium tuberculosis strains isolated from patients in Kazakhstan. Int $J$ Tuberc Lung Dis 2005, 9(10):1161-1167.

17. Cavusoglu C, Turhan A, Akinci P, Soyler I: Evaluation of the Genotype MTBDR assay for rapid detection of rifampin and isoniazid resistance in Mycobacterium tuberculosis isolates. J Clin Microbiol 2006, 44(7):2338-2342.

18. Miotto P, Piana F, Penati V, Canducci F, Migliori GB, Cirillo DM: Use of genotype MTBDR assay for molecular detection of rifampin and isoniazid resistance in Mycobacterium tuberculosis clinical strains isolated in Italy. J Clin Microbiol 2006, 44(7):2485-2491.

19. Mäkinen J, Marttila HJ, Marjamaki M, Viljanen MK, Soini H: Comparison of two commercially available DNA line probe assays for detection of multidrug-resistant Mycobacterium tuberculosis. J Clin Microbiol 2006, 44(2):350-352.

20. Brossier F, Veziris N, Truffot-Pernot C, Jarlier V, Sougakoff W: Performance of the genotype MTBDR line probe assay for detection of resistance to rifampin and isoniazid in strains of Mycobacterium tuberculosis with low- and high-level resistance. J Clin Microbiol 2006, 44(10):3659-3664.

21. Bwanga F, Hoffner S, Haile M, Joloba ML: Direct susceptibility testing for multi drug resistant tuberculosis: a meta-analysis. BMC Infect Dis 2009, 9:67.

22. WHO: Molecular line probe assays for rapid screening of patients at risk of multidrug-resistant tuberculosis (MDR-TB). Policy statement Geneva: World Health Organization; 2008

23. Barnard M, Albert H, Coetzee G, O'Brien R, Bosman ME: Rapid molecular screening for multidrug-resistant tuberculosis in a high-volume public health laboratory in South Africa. Am J Respir Crit Care Med 2008, 177(7):787-792

24. WHO: Guidelines for the surveillance of drug resistance in tuberculosis Geneva: World Health Organization; 2003.

25. Canetti G, Rist N, Grosset J: [Measurement of sensitivity of the tuberculous bacillus to antibacillary drugs by the method of proportions. Methodology, resistance criteria, results and interpretation.]. Rev Tuberc Pneumol (Paris) 1963, 27:217-272.

26. Vijdea R, Stegger M, Sosnovskaja A, Andersen AB, Thomsen VO, Bang D: Multidrug-resistant tuberculosis: rapid detection of resistance to rifampin and high or low levels of isoniazid in clinical specimens and isolates. Eur J Clin Microbiol Infect Dis 2008, 27(11):1079-1086.

27. Kent PT, Kubica GP: Public health mycobacteriology. A guide for level III laboratory Atlanta, GA: Centers for Disease Control and Prevention; 1985:94-96

28. Kamerbeek J, Schouls L, Kolk A, van Agterveld M, van Soolingen D, Kuijper S, Bunschoten A, Molhuizen H, Shaw R, Goyal M, et al: Simultaneous detection and strain differentiation of Mycobacterium tuberculosis for diagnosis and epidemiology. J Clin Microbiol 1997, 35(4):907-914.

29. van Embden JD, Cave MD, Crawford JT, Dale JW, Eisenach KD, Gicquel B, Hermans P, Martin C, McAdam R, Shinnick TM, et al:: Strain identification of Mycobacterium tuberculosis by DNA fingerprinting: recommendations for a standardized methodology. J Clin Microbiol 1993, 31(2):406-409.

30. Heersma HF, Kremer K, van Embden JD: Computer analysis of IS6110 RFLP patterns of Mycobacterium tuberculosis. Methods Mol Biol 1998 101:395-422.

31. Kremer K, Glynn JR, Lillebaek T, Niemann S, Kurepina NE, Kreiswirth BN, Bifani PJ, van Soolingen D: Definition of the Beijing/W lineage of Mycobacterium tuberculosis on the basis of genetic markers. J Clin Microbiol 2004, 42(9):4040-4049.

32. Brudey K, Driscoll JR, Rigouts L, Prodinger WM, Gori A, Al-Hajoj SA, Allix C, Aristimuno L, Arora J, Baumanis V, et al: Mycobacterium tuberculosis 
complex genetic diversity: mining the fourth international spoligotyping database (SpolDB4) for classification, population genetics and epidemiology. BMC Microbiol 2006, 6:23.

33. Stewart JE, Aagaard PJ, Pokorak EG, Polanskey D, Budowle B: Evaluation of a multicapillary electrophoresis instrument for mitochondrial DNA typing. J Forensic Sci 2003, 48(3):571-580.

34. Hillemann D, Rusch-Gerdes S, Richter E: Evaluation of the GenoType MTBDRplus assay for rifampin and isoniazid susceptibility testing of Mycobacterium tuberculosis strains and clinical specimens. J Clin Microbiol 2007, 45(8):2635-2640.

35. Huang WL, Chen HY, Kuo YM, Jou R: Performance assessment of the GenoType MTBDRplus test and DNA sequencing in detection of multidrug-resistant Mycobacterium tuberculosis. J Clin Microbiol 2009, 47(8):2520-2524

36. Akpaka PE, Baboolal S, Clarke D, Francis L, Rastogi N: Evaluation of methods for rapid detection of resistance to isoniazid and rifampin in Mycobacterium tuberculosis isolates collected in the Caribbean. J Clin Microbiol 2008, 46(10):3426-3428.

37. Van Rie A, Warren R, Mshanga I, Jordaan AM, van der Spuy GD, Richardson M, Simpson J, Gie RP, Enarson DA, Beyers N, et al: Analysis for a limited number of gene codons can predict drug resistance of Mycobacterium tuberculosis in a high-incidence community. J Clin Microbiol 2001, 39(2):636-641.

38. van Doorn HR, de Haas PE, Kremer K, Vandenbroucke-Grauls CM Borgdorff MW, van Soolingen D: Public health impact of isoniazidresistant Mycobacterium tuberculosis strains with a mutation at aminoacid position 315 of katG: a decade of experience in The Netherlands. Clin Microbiol Infect 2006, 12(8):769-775.

\section{Pre-publication history}

The pre-publication history for this paper can be accessed here: http://www.biomedcentral.com/1471-2334/10/149/prepub

doi: 10.1186/1471-2334-10-149

Cite this article as: Huyen et al., Validation of the GenoType ${ }^{\oplus}$ MTBDRplus assay for diagnosis of multidrug resistant tuberculosis in South Vietnam BMC Infectious Diseases $2010,10: 149$

Submit your next manuscript to BioMed Central and take full advantage of:

- Convenient online submission

- Thorough peer review

- No space constraints or color figure charges

- Immediate publication on acceptance

- Inclusion in PubMed, CAS, Scopus and Google Scholar

- Research which is freely available for redistribution

Submit your manuscript at www.biomedcentral com/submit
C Biomed Central 